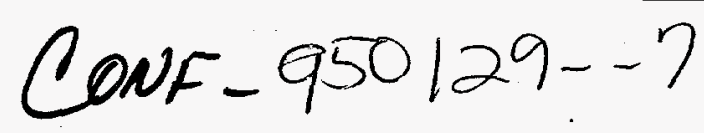

\title{
OPTIMIZATION OF THE GELCASTING OF A SILICON NITRIDE FORMULATION
}

O. O. Omatete, Oak Ridge National Laboratory, Oak Ridge TN 37831, J. P. Pollinger and Kevin O'Young, AlliedSignal Ceramic Components, Torrance, CA 90509.

\begin{abstract}
An optimum gelcasting condition for a silicon nitride formulation was determined using the Taguchi statistical method. An $\mathbf{L}_{8}\left(41 \times 2^{4}\right)$ design, in which the effects of one factor at four levels and four factors at two levels were evaluated in only eight experiments, was used. The factors at two levels were: the total monomer concentration, the monomer/crosslinker ratio, the initiator concentration, and the initiator/catalyst ratio; the factor at four levels was the initiator concentration per mass of the slip. The primary criterion used to determine optimum design was the green strength of the dried part, although three other parameters were measured: initial slip viscosity, time for the slip viscosity to reach $300 \mathrm{mPa} . s$ at $25^{\circ} \mathrm{C}$, and time for the slip to gel at $50^{\circ} \mathrm{C}$. The optimum gelcasting conditions from the designed experiments predicted $80 \%$ increase in green strength $(4.3 \mathrm{MPa}$ versus $2.4 \mathrm{MPa}$, the initial value). The confirmation runs showed only a $60 \%$ increase (3.8 $\mathrm{MPa})$.
\end{abstract}

\section{INTRODUCTION}

Gelcasting [1] is a generic ceramic forming process developed at the Oak Ridge National Laboratory. In gelcasting, we cast a suspension of commercial ceramic powder in a solution of organic monomers into a mold and polymerize it to form a green body which takes the shape of the mold. If the solvent for the monomers is organic, it is nonaqueous gelcasting [2]; if it is water, it is aqueous gelcasting $[3,4]$. In aqueous gelcasting, the solution consists of one or more monofunctional (one double bond) monomers and at least one multifunctional (at least two double bonds) cross-linking monomer and an initiator. Typically, the monomers are from the vinyl and allyl groups, and their homologues or derivatives.

In gelcasting a ceramic powder, the optimal selection of monomer, crosslinker and initiator can be onerous. For example, Table I [5] lists some monomers, crosslinkers and initiators that may be used in the gelcasting of silicon nitride. In this case, to determine an optimum combination by examining one factor at a time would require $224(8 \times 4 \times 7)$ experiments. Consequently, a fractional factorial experimental design was used to reduce the number of experiments. Even after the
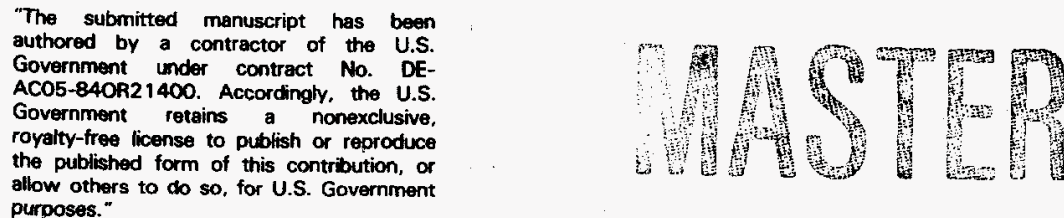


\section{DISCLAIMER}

Portions of this document may be illegible in electronic image products. Images are produced from the best available original document. 
combination of a monomer, a crosslinker, and an initiator has been identified, their optimal concentrations and processing conditions must be determined. Thus, the goal of this study was to determine the optimal gelcasting condition for the AlliedSignal Ceramic Components' GN-10 silicon nitride formulation in a nearproduction environment.

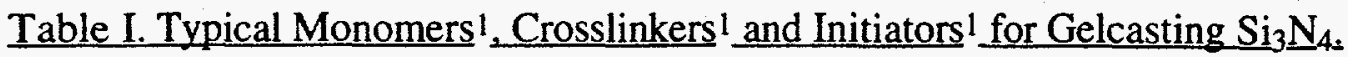

\begin{tabular}{ll} 
MONOMERS $^{*}$ & \multicolumn{1}{c}{ CROSSLINKERS } \\
\cline { 2 - 2 } MAM & MBAM \\
NVP & PEGDMA \\
MPEGMA & TAA \\
DiMAEMA & DADTA \\
DMAPMAM & \\
AA & \\
MA & \\
AM &
\end{tabular}

\begin{tabular}{l} 
INITIATORS \\
\hline APS \\
APS/TEMED \\
AIBN \\
AZIP \\
AZAP \\
$\mathrm{H}_{2} \mathrm{O}_{2}$ \\
TBHP
\end{tabular}

*Including their homologues and derivatives

1 List of Acronyms

MONOMERS:

MAM $=$ methacrylamide $\quad \mathrm{NVP}=\mathrm{N}$-vinyl pyrrolidone

MPEGMA = methoxy poly(ethylene glycol) methacrylate

DiMAEMA = dimethyl aminoethyl methacrylate

DMAPMAM = 3-N,N-dimethylaminopropyl methacrylate

$\mathrm{AA}=$ acrylic acid $\mathrm{MA}=$ methacrylic acid $\mathrm{AM}=$ acrylamide

CROSSLINKERS (CROSSLINKING MONOMERS):

MBAM = N,N'-methylene bisacrylamide

PEGDMA = poly (ethylene glycol) 1000 dimethacrylate

TAA = triallylamine

DATDA = diallyl tartardiamide

INITIATORS:

APS = ammonium persulfate $\quad$ AIBN = azobis (isobutyronitrile)

TEMED = N,N,N',N'-tetramethyl ethylene diamine

$\mathrm{AZIP}=$ azobis [2-(2-imidazolin-2yl)propane $] 2 \mathrm{HCl}$

AZAP = azobis (2-amidinopropane) $\mathrm{HCl} \quad \mathrm{H}_{2} \mathrm{O}_{2}=$ hydrogen peroxide

TBHP $=$ t-butyl hydroperoxide $\left(90 \%, 5 \% \mathrm{H}_{2} \mathrm{O}, 5 \% \mathrm{BuOH}\right)$

Gelcasting is a well defined process that has been applied to several ceramic powders [1]; for example, the detailed gelcasting of alumina has been reported [6]. Therefore, Taguchi method (quality engineering) [7] is appropriate for the optimization of the gelcasting of silicon nitride under industrial conditions. In increasing the amount of gelcasting slurry from a typical laboratory quantity of about $100 \mathrm{~g}$ to industrial values of $1 \mathrm{~kg}$ or more, simple scale-up resulted in insufficient processing time before the slurry gelled. The objective here, therefore, was to increase the processing time while optimizing the green strength of the dried parts. 


\section{PROCEDURE}

The system chosen for gelcasting silicon nitride in this study consisted of: monomer = MAM, crosslinker $=$ MBAM, and initiator system = APS/TEMED. (See Table I for an explanation of the acronyms). After brainstorming, five controlling factors (independent variables) were selected: the total monomer (MAM + MBAM) concentration, the ratio of the monomer to the crosslinker (MAM/MBAM), the initiator (APS) concentration, the ratio of the initiator to the catalyst (APS/TEMED), and the amount of APS added per mass of slip. Four of the factors were tested at two levels, high $(\mathrm{H})$ and low (L). Because the amount of APS per unit mass of slip strongly determines the gelation rate, it was tested at four levels, lowest (LL), low, high, and highest $(\mathrm{HH})$. The experimental design selected was $L_{8}(41 \times 24)$ in which the effects of one factor at four levels and four factors at two levels were evaluated in only eight experiments $[7,8]$. Table II shows the factors, their levels and combinations in the experimental design. Four response parameters (dependent variables) were measured: initial slip viscosity, $\eta(\mathrm{mPa} . \mathrm{s})$, at ambient conditions; time, $\mathrm{TG}(\mathrm{min})$, for the slip to gel at $50^{\circ} \mathrm{C}$; time, $\mathrm{TV}(\mathrm{min})$, for the slip viscosity to reach $300 \mathrm{mPa} . s$ at $25^{\circ} \mathrm{C}$; and the strength, $\sigma(\mathrm{MPa})$, of dried gelcast $\mathrm{Si}_{3} \mathrm{~N}_{4}$ discs.

Table II. Factors, levels and their combination for the $\mathbf{L}_{8}\left(41{ }^{1} \mathbf{2}^{4}\right)$ design.

\section{FACTORS}

A (MAM+MBAM) conc.
B $\mu$ LPS/100 g slip
C MAM/MBAM
D APS conc.
E APS/TEMED

\section{LEVELS}

$\begin{array}{lll}2 & 3 & 4 \\ \mathrm{H} & & \\ \mathrm{L} & \mathrm{HH} & \mathrm{LL} \\ \mathrm{H} & & \\ \mathrm{L} & & \\ \mathrm{H} & & \end{array}$

\begin{tabular}{|c|c|c|c|c|c|c|}
\hline Experiment & \multicolumn{5}{|c|}{ Factors and the level combinations } & Measured \\
\hline No. & $\underline{\mathbf{A}}$ & $\underline{\mathbf{B}}$ & $\underline{\mathbf{C}}$ & $\underline{\mathbf{D}}$ & $\underline{\mathbf{E}}$ & Variable \\
\hline$\overline{1}$ & 1 & $\overline{1}$ & $\overline{1}$ & $\overline{1}$ & $\overline{1}$ & $\mathrm{Y}_{1}$ \\
\hline 2 & 1 & 2 & 1 & 2 & 2 & $Y_{2}$ \\
\hline 3 & 1 & 3 & 2 & 1 & 2 & $Y_{3}$ \\
\hline 4 & 1 & 4 & 2 & 2 & 1 & $\mathbf{Y}_{4}$ \\
\hline 5 & 2 & 1 & 2 & 2 & 2 & $\mathrm{Y}_{5}$ \\
\hline 6 & 2 & 2 & 2 & 1 & 1 & $Y_{6}$ \\
\hline 7 & 2 & 3 & 1 & 2 & 1 & $Y_{7}$ \\
\hline 8 & 2 & 4 & 1 & 1 & 2 & $\mathrm{Y}_{8}$ \\
\hline
\end{tabular}

For each experiment, approximately $1 \mathrm{~kg}$ of a $50 \mathrm{vol} \%$ solids suspension was prepared by measuring the calculated amount of the components $\left(\mathrm{Si}_{3} \mathrm{~N}_{4}\right.$ powder, sintering aids, dispersants, monomer, crosslinker and water) and ball-milling them for a given number of hours. The amount of each component was determined by 
the experiment number in Table II; No. 1 was the standard process set-up. After milling, the slurry was de-aired and the calculated amount of initiator and catalyst as indicated in Table II were mixed into the slip. After another de-airing step, the viscosity, specific gravity, and $\mathrm{pH}$ of the slip were measured at ambient conditions. To determine the time they took to gel, samples were placed in an oven set at $50^{\circ} \mathrm{C}$. A sample was placed in a Brookfield Digital Rheometer Model DV-II to measure the time for its viscosity to rise to $300 \mathrm{mPa}$.s at $25^{\circ} \mathrm{C}$. Several disc molds $(25 \mathrm{~mm}$ diameter $x 5 \mathrm{~mm}$ thick) were filled with the slip and gelled in a second oven set at $50^{\circ} \mathrm{C}$. The gelled $\mathrm{Si}_{3} \mathrm{~N}_{4}$ discs were dried and their tensile strength was measured by a diametral compression test [9]. The remaining slip was used to cast other parts such as plates or turbine wheels. To compare with the predicted value, two confirmation runs were made at the optimum levels determined from the experimental design. These levels are shown in Table IV, the result of the runs in Table III, and both are discussed in the next section.

\section{RESULTS AND DISCUSSIONS}

Table III shows a set of typical measured variables for the eight experiments. The slip properties measured at ambient conditions exhibited minimal variations indicating the slip preparation was consistent. However, the gelation times and the strength varied with the experimental conditions. The average strengths in the Table were calculated from the measurement of a minimum of five to a maximum of twenty dried gelcast $\mathrm{Si}_{3} \mathrm{~N}_{4}$ discs, with a pooled standard deviation of $0.25 \mathrm{MPa}$.

\section{Table III. Typical Measured Variables for the Eight Experiments.}

\begin{tabular}{|c|c|c|c|c|c|c|}
\hline \multirow{2}{*}{ Expt No. } & \multicolumn{3}{|c|}{ Slip Properties } & \multicolumn{2}{|c|}{ Gelation Time } & \multirow{2}{*}{$\frac{\text { Avg. Strength }}{\sigma(\mathrm{MPa})}$} \\
\hline & $\mathrm{pH}$ & $\underline{\mathrm{SG}}$ & $\eta(\mathrm{mPa} . \mathrm{s})$ & $\mathrm{TV}(\min )$ & $\mathrm{TG}(\mathrm{min})$ & \\
\hline 1 & 8.96 & 2.068 & 76 & 6.5 & 45 & 2.41 \\
\hline 2 & 9.21 & 2.069 & 62 & 12.5 & 145 & 1.05 \\
\hline 3 & 8.83 & 2.055 & 88 & 6.5 & 45 & 2.24 \\
\hline 4 & 9.35 & 2.060 & 55 & 80.0 & 220 & 0.50 \\
\hline 5 & 9.22 & 2.041 & 57 & 27.0 & 130 & 1.61 \\
\hline 6 & 8.80 & 2.050 & 74 & 9.5 & 90 & 3.90 \\
\hline 7 & 9.02 & 2.043 & 55 & 23.5 & 135 & 4.26 \\
\hline 8 & 9.30 & 2.041 & 55 & 33.0 & 135 & 3.47 \\
\hline \multicolumn{7}{|c|}{ Confirmation Runs } \\
\hline 1 & 8.93 & 2.047 & 62 & 14.5 & 110 & 3.75 \\
\hline 2 & 9.30 & 2.049 & 72 & 11.0 & 95 & 3.89 \\
\hline
\end{tabular}

The effect of a factor at a given level was calculated by averaging the data over that factor level. For example, in Table II, the effect of factor $\mathbf{A}$ at level 1 is $\left(Y_{1}+Y_{2}+Y_{3}+Y_{4}\right) / 4$, at level 2, it is $\left(Y_{5}+Y_{6}+Y_{7}+Y_{8}\right) / 4$. Similarly, the effect of factor $E$ at level 1 is $\left(Y_{1}+Y_{4}+Y_{6}+Y_{7}\right) / 4$, at level 2, $\left(Y_{2}+Y_{3}+Y_{5}+Y_{8}\right) / 4$. Factor $B$ with four levels has only two data points at each level. Thus, the effect of factor $\mathbf{B}$ 
at level 1 is $\left(Y_{1}+Y_{5}\right) / 2$, at level 2 , it is $\left(Y_{2}+Y_{6}\right) / 2$ and so on. Table IV is the response Table showing the calculated effect of each factor at the different levels and the absolute value of their differences. The effects at all the four levels of factor $\mathbf{B}$ (the amount of the initiator per mass of slip) are shown and the difference value here is between level 1 and the level with highest value.

Table IV. The Response Table for Measured Parameters ( $\sigma$. TV. \& TG).

Measured Variable, Strength $(\sigma, \mathrm{MPa})$

\begin{tabular}{|c|c|c|c|c|c|}
\hline FACTOR & $\underline{\mathbf{A}}$ & B & C & $\underline{\mathbf{D}}$ & \\
\hline Level 1 & 1.55 & 2.01 & 2.80 & 3.00 & 2.77 \\
\hline Level 2 & 3.31 & 2.48 & 2.06 & 1.86 & 2.09 \\
\hline Level 3 & & 3.25 & & & \\
\hline Level & & 1.99 & & & \\
\hline$|(\Delta)|$ & 1.76 & 1.24 & $\underline{0.74}$ & 1.14 & 0.68 \\
\hline
\end{tabular}

Measured Variable, Time (TV, min) to reach $300 \mathrm{mPa} . \mathrm{s}$ at $25^{\circ} \mathrm{C}$.

\begin{tabular}{lllllll}
\hline FACTOR & $\underline{\mathbf{A}}$ & $\underline{\mathbf{B}}$ & $\underline{\mathbf{C}}$ & $\underline{\mathbf{D}}$ & $\underline{\mathbf{E}}$ \\
\hline Level & 1 & 26.4 & 16.8 & 18.9 & 13.9 & 29.9 \\
Level & 2 & 23.3 & 11.0 & 30.8 & 35.8 & 19.8 \\
Level & 3 & & 15.0 & & & \\
Level & 4 & & 56.5 & & & \\
I(A)I & $\underline{3.1}$ & $\underline{39.7}$ & $\underline{11.9}$ & $\underline{21.9}$ & $\underline{10.1}$
\end{tabular}

Measured Variable. Time (TG, $\min$ ) to Gel at $50^{\circ} \mathrm{C}$.

\begin{tabular}{|c|c|c|c|c|c|}
\hline FACTOR & $\underline{\mathbf{A}}$ & $\underline{\mathbf{B}}$ & & $\underline{\mathbf{D}}$ & \\
\hline Level 1 & 113.8 & 87.5 & $\overline{11} 5.0$ & 78.8 & $\overline{12} 2.5$ \\
\hline Level 2 & 122.5 & 117.5 & 121.3 & 157.5 & 113.8 \\
\hline Level 3 & & 90.0 & & & \\
\hline Level & & 177.5 & & & \\
\hline$|(\Delta)|$ & 8.8 & 90.0 & 6.3 & 78.7 & \\
\hline
\end{tabular}

Confirmation Levels

$\begin{array}{llllll}\text { FACTOR } & \frac{\mathbf{A}}{2} & \frac{\mathbf{B}}{2} & \frac{\mathrm{C}}{1} & \frac{\mathbf{D}}{1} & \frac{\mathbf{E}}{1}\end{array}$

The confirmation levels were based primarily on optimizing the strength (with its larger-the-better characteristic); that is, the largest possible value of strength is desired. Thus, for each factor, the level with the highest strength (A-2, B-3, C-1, D-1, and E-1) should have been selected. However, another requirement of the design is that there should be sufficient processing time before the slip gelled. This implies that the times TV and TG should be larger than a minimum value. As the actual data in Table III show, the worst strength was in experiment No. 4 which had the largest times while the highest strengths were at intermediate times. The confirmation levels shown in Table IV, B-2 was used instead of B-3 in order to obtain intermediate gelation times; B-1 and B-3 were fast, and B-4 was very slow. 
The times for the actual confirmation runs in Table III show this; they are intermediate between the times for the eight experiments.

In the Taguchi method, once the confirmation levels have been determined, the predicted values may be calculated based either on simple averaging or on the signal-to-noise ratio $[7,8]$. In this study, the prediction was by simple averaging and, to minimize over-estimation, only the three strongest effects (A-2, B-3 and D1) were used. The predicted strength was $4.3 \mathrm{MPa}$ which is an $80 \%$ increase over the value for experiment No.1, the standard conditions. The average result of the two confirmation runs shown in Table III was $3.4 \mathrm{MPa}$, a $60 \%$ increase over the standard conditions. The confirmation values were, however, less than the predicted value which was based on only three effects. If all the effects of the five factors were additive, the confirmation values would have been at least equal to the predicted value. This discrepancy implies that there are interactions among the factors. In the confirmation runs, the gelation times were intermediate between the highest and the lowest values obtained in the experiments, as was predicted. Also in these runs, the slip properties were consistent. A surprising finding of this study was that increasing the crosslinker ratio did not correspond to an increase in the green strength of the dried gelcast parts.

\section{CONCLUSIONS}

A strategy for the optimization of the gelcasting of the AlliedSignal Ceramic Components' GN-10 silicon nitride formulation in large, production-size batches using the Taguchi method has been demonstrated. The slip properties of all batches were consistent, indicating that the processing was reproducible. The two desired goals of the optimization were achieved. At the optimum conditions, the gelation time was increased thus providing adequate processing time before gelation commenced. The green strength of the dried gelcast parts was increased by nearly $60 \%$ to $3.4 \mathrm{MPa}$. However, because this was less than the $80 \%$ increment predicted, there are interactions between the factors that were selected. Nevertheless, this initial study has identified improved processing conditions which provide the basis for further optimization. In addition, this investigation has shown that increasing the crosslinker-to-monomer ratio in the gelcasting process does not produce a corresponding increase in the green strength, a finding which was unexpected and needs to be studied further.

\section{ACKNOWLEDGEMENT}

Research is sponsored by the US Department of Commerce, National Institute of Science and Technology Advanced Technology Program and the US Department of Energy, Assistant Secretary of Energy Efficiency, office of Transportation Technologies, as part of the Ceramic Technology Project of the Materials Development Program, under contact DE-AC05-840R21400 with Martin Marietta Energy Systems, Inc. The authors thank M. A. Janney, S. D. Nunn and R. J. Lauf for reviewing the manuscript.

\section{DISCLAIMER}

\footnotetext{
This report was prepared as an account of work sponsored by an agency of the United States Government. Neither the United States Government nor any agency thereof, nor any of their employees, makes any warranty, express or implied, or assumes any legal liability or responsibility for the accuracy, completeness, or usefulness of any information, apparatus, product, or process disclosed, or represents that its use would not infringe privately owned rights. Reference herein to any specific commercial product, process, or service by trade name, trademark, manufacturer, or otherwise does not necessarily constitute or imply its endorsement, recommendation, or favoring by the United States Government or any agency thereof. The views and opinions of authors expressed herein do not necessarily state or reflect those of the United States Government or any agency thereof.
} 


\section{REFERENCES}

1. O. O. Omatete, M. A. Janney \& R. A. Strehlow, "Gelcasting-A New Ceramic Forming Process," Ceramic Bulletin, 70 [10], Oct 1991.

2. M. A. Janney, "Method for Forming Ceramic Powders into Complex Shapes," U.S. Patent No. 4,894,194, January 16, 1990.

3. M. A. Janney \& O. O. Omatete, "Method for Molding Ceramic Powders using Water-Based Gel Casting," US Patent No. 5,028,362, Jul. 2, 1991

4. M. A. Janney \& O. O. Omatete, "Method for Molding Ceramic Powder Using a Water-Based Gelcasting Process," U.S. Patent No. 5,145,908, Sept. 8,1992.

5. M. A. Janney \& O. O. Omatete, "Development of Low-Toxicity Gelcasting Formulations - I," Paper SVIII-67-94, ACerS's 96th Annual Meeting, Indianapolis, IN, April, 1994.

6. A. C. Young, O. O. Omatete, M. A. Janney, \& P. A. Menchhofer, "Gelcasting of Alumina," J. Am. Ceram. Soc., 74 [3] 612-18 (1991).

7. G. Taguchi, "Introduction to Quality Engineering," Asian Productivity Organization, Tokyo, Japan (1986).

8. "Taguchi Methods - Implementation Manual," American Supplier Institute, Dearborn, MI, 1992.

9. S. D. Nunn, O. O. Omatete, C. A. Walls and D. L. Barker, "Tensile Strength of Dried Gelcast Green Bodies," Ceram. Sci. \& Engr. Proceed., 15, [4], 493-8, 1994. 